\title{
Agency of the instructional designer: Moral coherence and transformative social practice
}

\author{
Katy Campbell \\ University of Alberta \\ Richard A. Schwier \\ University of Saskatchewan \\ Richard F. Kenny \\ Athabasca University
}

\begin{abstract}
In this paper we propose a view of instructional design practice in which the instructional designer is an agent of social change at the personal, relational, and institutional levels. In this view designers are not journeymen workers directed by management, but act in purposeful, value based ways with ethical knowledge, in social relationships and contexts that have consequences in and for action. The paper is drawn from the data set of a threeyear study of the personal meaning that instructional designers make of their work, in a world where identities rely less on institutionally "ascribed status or place" than on the spaces that we make as actors in the social world. Through the voices of two instructional designers in this study, we begin to make the case for instructional design practice as ethical knowledge in action, and for how agency emerges from the designer's validated sense of identity in institutions of higher learning.
\end{abstract}

\section{Introduction}

Practice is a good deal more than the technical things we do in classrooms it relates to who we are, to our whole approach to life (Goodson, 1994, p. 29)

The instructional design field has long debated the nature of instructional design practice. Is it a craft? Is it a science? Is it an art? In each view, the designer interacts with models and content -- moving from a workbench to a laboratory to a studio -- but in ways constrained by technical knowledge, cultural boundaries, and somewhat confounded identities. In these conceptions instructional designers act on content to externally defined expectations. We propose an alternative view, in which the instructional designer is an agent of social change at the personal, relational, and 
institutional levels. In this view designers are not journeymen workers directed by management but act in purposeful, value based ways with ethical knowledge, in social relationships and contexts that have consequences in and for action.

As instructional designers, and teachers and scholars of instructional design, we have become critical of our own understanding and practice and skeptical about the "grand narratives" of instructional design, for example, the traditional models of instructional design process that portray it as a rational, systematic, objective process based on the purposeful implementation of the principles of behavioural and cognitive science (cf. Braden, 1996; Dick, 1996; Gustafson \& Branch, 1997; Kenny, Zhang, Schwier \& Campbell, 2004; Willis, 1998, 2000). From our own work as instructional designers, we suspect that instructional designers do not always, or even mostly, practice in ways that can be measured, quantified, and scientifically described (Wood, 1992) but that they act out of their own values and convictions about the social purposes of design. We think that the instructional design process in higher education at least, in which faculty, designers, and others develop new ideas and understandings through conversation, may be a form of cultural learning or collaborative learning that leads to cultural change. In other words, we propose that rather than occupying the lowest rung of the professional ladder, that of the technicians who "do what they are told" by putting The Theory into practice (Wood, 1992), instructional designers can, and do, challenge and shape the institutional "discourse" about the purposes and forms of learning. What do we mean by change agency, and what implications does this view have for the practice of instructional design?

At the core, change agency is a moral relationship with others. Fundamentally we believe that instructional design practice is not grounded in the rationality of behaviourism as much as in a "social morality in which caring values are central but contextualised in webs of relationships and constructed towards communities" (Christians, 2000, p. 142). Practice is embodied in the designer's core values and beliefs: Herda (1999) suggests that ethical knowledge, or moral judgment, can neither be learned nor forgotten; that it characterises all authentic understanding and action. The consensual act of instructional design is a social, relational process created and shared through language, itself a form of action (Herda, 1999). For example, when we engage faculty in a conversation about the consequences of designing for active learning, including the development of critical thinking skills, we are "altering and changing (a) social context (and), those statements, themselves, contribute significantly to a basis for personal and social change" (Herda, 1999, p. 26). In this way design is a moral and political act, not merely a technical one. 
Acting from ethical knowledge -- with moral agency -- implies a reflexive knowledge of self in action, an understanding of "one's biography, present circumstances, deep commitments, affective investments, social context and conflicting discourses" (Britzman, 1991, p. 8), about what it means to be an instructional designer in an institution of authoritative discourse about the monologic sources of knowledge and power, and one's role in it. Although she refers specifically to teacher education, we agree with Britzman (1991) that designing with moral authority "concerns coming to terms with one's intentions and values, as well as one's knowing, being and acting in a setting characterised by contradictory realities, negotiation, dependency, and struggle" (p. 8). To be agents of social change, designers must not only hold certain values, but also be conscious of them, and be able to articulate the choices for action that embody them. In this view, instructional design is purposeful and critical.

This paper is drawn from the data set of a three-year study of the personal meaning that instructional designers make of their work, in a world where identities rely less on institutionally "ascribed status or place" than on the spaces that we make as actors in the social world. There are several purposes for this study and its products. As a reflexive project we share our stories as practitioners and, as conversational partners and in community, "reformulate our conceptions of identity and self-hood" (Goodson, 1995, p. 3). In this way the project itself is one of agency and transformation. Here, through the voices of two instructional designers in the study, we begin to make the case for instructional design practice as ethical knowledge in action, and for how agency emerges from the designer's validated sense of identity in institutions of higher learning. This is one of a series of completed (cf. Campbell, Gibson \& Gramlich, 2004; Schwier, Campbell \& Kenny, 2004) and developing papers that will explore identity, agency and community and challenge the grand narratives of instructional design.

\section{The theoretical challenge}

We use the following theoretical constructs to challenge the discourses that contextualised instructional design as a rational, technical, non-subjective process. The study this paper represents is embedded in two theoretical constructs: instructional design as a social construct and critical pedagogy, in which designers act as agents of social change. In post-structuralist terms, we propose that instructional design practice is constituted by socially and culturally produced patterns of language, or discourse, with socially transformative power through the positioning of the self in explicit action (Francis, 1999). This construct is contrary to the idea of instructional design as decontextualised science. In other words, we view instructional 
design as a socially constructed practice rather than a technology to be employed.

In addition to the social implications of practice, we recognise that instructional design exists within a larger context of social change. Research on change and change management is multi-disciplinary, drawing on fields such as organisational behaviour, sociology, psychology, economics, and anthropology, and the education literature is replete with useful advice for leaders who are part of the change process in large systems - and particularly school systems (Fullan, 2001; 2004). We argue that the process of change is particular to the context in which it occurs in this case, instructional design in higher education, and it also has temporal characteristics. For example, Weick and Quinn (1999) suggested that change is either episodic or continuous. Episodic change refers to an infrequent and discrete kind of change, typically change that occurs once and is contained. Continuous change on the other hand refers to ongoing change, often change that occurs over time and that may resonate beyond the system within which the change initially occurs. While many products of instructional design are episodic (eg., changes to a course are completed and implemented), the process and influence of instructional design is better understood as continuous.

Whether continuous or episodic, most change models fall into two broad categories: planned change and unplanned change. Planned change is deliberate, and it is normally the outcome of conscious reasoning based on some clear expectations. For example, the explicit practices of instructional design, and most models of instructional design, promote the idea that instructional design is a deliberate process that emphasises planned approaches to development. But change has unplanned features that can introduce desirable or undesirable consequences, and instructional design similarly embraces tacit, creative and spontaneous elements that can influence the quality of outcomes. In order to maximise the benefits of change and avoid unintended consequences, change must be effectively managed, including social negotiation among individuals and groups, and larger transformational changes (Bolman \& Deal, 1997). This is a particular challenge to instructional designers, given that professional programs in ID pay little or no attention to change or change management strategies, perhaps because it is an adolescent field of study and practice that is growing away from its original heritage (Hill, Bichelmeyer, Boling, Gibbons, Grabowski, Osguthorpe, Schwier \& Wager, 2004).

The roots of ID are well known. Instructional design as a field came of age after World War II, and was originally based on the behaviourist learning theories of Skinner, and Thorndike, among others (Saettler, 1992). That is, instructional design was based on the empiric assumption that behaviour is 
predictable, and that educational design can occur in isolation from the contexts in which learning will take place (Koper, 2000). As a result, the language of traditional instructional design reflects a systematic approach based on social engineering and reflects the values of efficiency and effectiveness (cf. Braden, 1996; Dick, 1996; Dick \& Carey, 1996; Merrill, 2002; Merrill \& ID2 Research Group, 1996). Traditional instructional design models describe an expressly linear, systematic, prescriptive approach to instructional design (Andrews \& Goodsen, 1991; Braden, 1996; Wedman \& Tessmer, 1993) and are strongly objectivist in nature (Jonassen, 1999). Although most authors have moved away from strict linearity and their approaches are less explicitly prescriptive, systematic models continue to thrive in various portrayals (eg., Morrison, Ross \& Kemp, 2004; Seels \& Glasgow, 1998; Smith \& Ragan, 2005) and continue to be taught to thousands of graduate students (Willis, 1998).

These are supposedly value free ways of shaping and representing knowledge based on the assumption that educational technologies and environments are neutral and democratic, that knowledge can be codified and presented in templates or blueprints that describe what knowledge is in a "known world." Designers, programmers, and media developers emerging from this "scientific" field have learned models that value objective, rational, instrumental, and empirical approaches. Critics like Garrison (1993) and Vrasidas (2001) have described the products and environments they produce and deliver as too often prescriptive, formalistic, restrictive, and reductionist, due in no small way to the culture instructional designers have acquired within their areas of study and the training that they have received. Carter (2000) asks, "How aware and concerned are distance educators, instructional designers, and educational technologists about critical pedagogy, critical multiculturalism, and the powerful political nature of technological systems and their cultural practices?" (p. 28).

A cultural shift has been occurring over the past decade in education -- a shift towards environments and approaches based on the ideas of social constructivism. In this worldview, learning is situated in rich contexts, and knowledge is constructed in communities of practice through social interactions. Cobb (1996) argues that knowledge is not held objectively, but is unique, wholly subjective, and passed on by establishing common ground between the knower and the learner. This common ground must embrace interests and personal values, which requires a sharing at both the socio-cultural and the cognitive levels (Ewing, Dowling, \& Coutts, 1998, p. 10). In other words, the instructional designer's practice, to which self reflection is critical, will reflect his or her values and belief structures, understandings, prior experiences, and construction of new knowledge through social interaction and negotiation. Certainly, it is true that, over 
the past decade, the field of instructional design has experienced the strong influence of constructivist learning theory and a shift from teacher controlled to learner centred instruction (Reigeluth, 1996; 1999), and this movement has led to the emergence of a number of ID models based on constructivist learning principles (eg., Cennamo, Abell \& Chung, 1996; Hannafin, Land \& Oliver, 1999; Jonassen, 1999; Mayer, 1999; Shambaugh \& Magliaro, 2001; Willis, 2000).

What is less certain is whether instructional designers are being taught or are using such models in their practice. A recent review (Kenny, Zhang, Schwier \& Campbell, 2005) has indicated that instructional designers tend to follow the techniques delineated by traditional, process based models, although they do not follow them in a rigid fashion and also engage in a wide variety of other tasks that are not reflected in ID models, such as communications, editing, project management and team building.

In addition to these other activities, instructional designers also widely engage in faculty development (Kenny, Zhang, Schwier \& Campbell, 2005) through both formal and informal learning processes. In this regard, we believe that faculty working with instructional designers in development projects are actually engaging, as learners, in a process of professional and personal transformation that has the potential to transform the institution. Some theorists (cf. Glaser, 1991; Jonassen Dyer, Peters, Robinson, Harvey, King \& Loughner, 1997; Tergan, 1997) believe that learning is most effective if it is embedded in social experience, and if it is situated in authentic problem solving contexts entailing cognitive demands relevant for coping with real life situations. Learning occurs through social intercourse, or design conversations. Even though much continues to be written about the effect of technology and computers on society, designers have not necessarily recognised their agency in the development of a knowledge economy that reflects culturally biased views of teaching, learning, and the construction of knowledge. We believe that instructional designers have not been encouraged to examine their cultural values and assumptions critically, and we challenge the idea that the expert knowledge of designers, gained through education, experience and interaction, should remain unexamined.

\section{The research design}

The stories reported in this article were drawn from a three-year (20022005) study involving, to date, twenty instructional designers at six Canadian universities. Initially, we selected participants from Medical Doctoral Universities, those with a broad range of PhD programs and research, as well as medical schools. The participating institutions also have an administrative and/or academic unit whose mandate is to support 
faculty developing (usually) technology enhanced, "blended", or online learning environments; and/or an "Extension Division", that employs at least two instructional designers.

Participation was elicited through a range of strategies including personal email invitations, advertisements on lists and in institutional communications platforms, personal contacts at professional meetings and through collaborative projects, membership lists from professional associations, contacts through delegate lists from conferences, and visits to graduate classes. Sources of data include research conversations with instructional designers, email, and group meetings and/or focus groups.

The main study is constructed as a narrative inquiry conducted mainly through the development of collaborative conversations. The "opening gambits" - designed to encourage designers to explore what they know, how they know it, and how this influences their actions in the particular sociocultural contexts in higher education - referred to their lives as learners and their memberships in social and professional communities, their career choices, their core values about the purposes of education and of design, and their design practices.

Narrative inquiry and the storying of experience are socially and contextually situated interpretive practices, starting from the personal as "personal knowledge has a practical function, not in a technical sense, or as an instrument for previously determined outcomes, but... as a source for deliberation, intuitive decisions, daily action and moral wisdom" (Conle, 2000 , p. 51). Narrative inquiry is transformative, because in defining how to become engaged as students of our own practice, the practice itself is examined and understood. In this way, thinking about and telling stories of practice requires a critical, reflective engagement leading to changed or transformed practice. Thus the methodological approach for the study mirrors a social constructivist framework for instructional design practice, which is one of social interaction and construction of meaning through conversation.

The two conversations included in this paper were selected from the pool of data because these participants chose to discuss elements of their professional identities and performance that were tied to moral/ethical dimensions of their work and their roles as agents of social change. These conversations were not unique; other participants also discussed these dimensions of their work. But they were particularly clear, powerful and focused on these dimensions, probably more than the conversations with other people we interviewed. And the two participants approached the issues from very different directions - one more intimately/personally, and one more globally/politically. So, in other words, they were selected not 
because we were looking to generalise findings from the entire group, but rather because we felt these participants gave thoughtful, articulate, and divergent descriptions of their social agency, the moral stances that guide their work, and the transformations they have influenced and experienced.

Transcripts of the conversations are independently coded by two researchers. Transcripts are analysed using Atlas ti ${ }^{\mathrm{TM}}$ software, and as themes emerged, they are shared with the research team and the participants, and used to construct networks of meaning. This reflexive process is intended to further engage participants in identifying emerging personal and community issues related to instructional design by bringing the personal and community problems of practice into self awareness, leading to social action. In this way, narrative inquiry involves the "politics of identity construction and ongoing identity maintenance", where the lived experiences of instructional designers can "be used as the sites wherein and whereby we interrogate the social world theoretically and critically" (Goodson, 1995, p. 4).

\section{Two stories of design: Ethical knowledge in practice}

In this paper we have chosen to exemplify the moral integrity of instructional design practice through the stories of two designers, illuminating how their values and beliefs embody the relational work they choose to do, and the ways in which they engage their own agency. Professionally prepared in unrelated disciplines, each of these designers came to instructional design through career paths and life and work experiences that have critical dimensions. Power is "the ability to take one's place in whatever discourse is essential to action and the right to have one's part matter" (Heilbrun, 1988, p. 18). In this excerpt from Writing a Woman's Life, Carolyn Heilbrun speaks of the power to be able to participate in culturally contextualised work of the higher education institution in ways that make a social and critical difference.

In some ways, making a critical difference demands subversion of the dominant discourse; in these stories subversion is a positive, generative power. We have chosen these stories for this paper because they are imbued with the personal, moral strength key to a particular design ethics in practice. Each is a story of agency, yet they reveal what we think are somewhat different and complementary agencies, played out at different levels of personal, institutional, and societal engagement. Laura's agency is experienced and enacted at the level of the personal - agency in a web of personal relationships - that we have described as agency for social change. David's agency is less embedded in the personal and appears more externally directed: we speculate that this relates to agency for social justice. As our research progresses we are curious about how these two 
agencies develop and interact in the sociopolitical contexts of higher education. And we are curious about the agentic zones of designers and the faculty with whom they work.

\section{Laura's design ethic in practice}

On the advice of a classroom teacher Laura's parents placed her in drama activities when she was ten years old, which "fundamentally shaped" her. She described an integrated approach to teaching writing during her teaching practice, in which she would use art, drama and physical activity to create a safe and caring environment for children who had "clinical depression, ADHD, severe learning problems;" given the economic status of the neighborhood she'd bring snacks from home because she worried about their nutrition. She described how, in the context of a novel study, she would take them outside for physical activity where she would, for example, have them "pretend that they were mice running in this field and this hawk was about to get them ... and they had to hide and crouch down." Laura characterises her values as "holistic -- learning involves the body and knowing is embodied". She is conflicted about the disembodiment of online learning. She says, "(We're) having a written discussion online... we're not talking online. We are in actuality, typing; meanwhile all our body is learning is to sit stationary in front of a screen..."

Laughing, she noted the family "theory of getting kids tired out by running a lot," and related her "philosophy of teaching stems a lot from their philosophy of raising me." A key event in shaping her worldview occurred when she was in high school and she observed a friend's encounter with racism: her struggles drove Laura to "look at human rights and to reexamine my own prejudices in life and that really drove me into the area of human rights (in graduate work)." With an emphasis on spiritual and physical well being as a way of coping, the same friend influenced Laura as a designer. While wanting to shape active, social, holistic and equitable learning environments, Laura is at the same time deeply conflicted about the "critical social issues surrounding the use of technology." Laura partially attributes the development of her identity as a critical instructional designer to a graduate supervisor who would engage in debates with her "about the socially constructed nature of technology and the inability to develop a technology based learning environment that didn't have a cultural bias."

Her values were challenged in a job developing materials for a company that delivered expensive training to hard to employ populations of young, single mothers, aboriginals, and new Canadians, "this was very lucrative process for a company willing to exploit". Appalled at the cost of tuition 
paid by the clients and the company's lack of integrity, Laura resigned because she "just couldn't support their business practices with my degree." Laura achieves a degree of moral coherence when she is able to work with third world development projects where her commitment to human rights allows her to challenge the assumptions of what she terms "the neoconservative stance" to education. Her design ethic in practice is framed by the notion of conversation communities in which all members are morally accountable.

When we asked Laura to tell us a story of practice embodying her values of holistic learning that is socially responsible, she told one of professional and personal transformation for learners, faculty, and herself in a medical course designed for rural health care practitioners.

\section{The Health Care Team: Challenging cultural myths}

Laura is one of several designers in an academic support centre in a Western university for faculty who were developing blended learning environments. One of many programming initiatives, the unit offered up to $\$ 500$ to faculty as seed funding for an instructional development project. One proposal requested a digital camera to support an information site for resources (texts, images; educational support) and emerging practices in end of life care. The faculty member, a new tenure stream appointment in the Faculty of Health Care, had had to cope with the complex physical, emotional, cognitive, social, and spiritual issues of the dying and their communities in his practice as a young rural physician. As he struggled to find the resources he needed he became determined to make them available to his colleagues around the world; he took up his faculty appointment at a time the Internet was becoming a more stable and accessible delivery platform.

The mission of Laura's unit was to support and enhance reflective practice in the development of transformative learning environments. Although many faculty clients would have preferred an arm's length production orientation, the unit took a faculty learning view through active inclusion on a collaborative instructional development team. Dr B. wanted a tool to develop a website; here was an opportunity to involve him in a project to transform the way in which medical professionals learn in their workplaces. Bemused, Dr B. was drawn into designing a case based, interdisciplinary, continuing professional medical education course. The design involved virtual health care teams composed of physicians, nurses, residents, and pharmacists working equitably and collaboratively to resolve end of life care issues with the support of a facilitative group of rural physicians and nurses, a spiritual advisor, a pharmacist, and a sociologist. 
Coming from a family associated with the health professions, Laura's pedigree, or her "knowledge of the day to day life of a medical family," helped her establish an "immediate rapport" with Dr B. and an emotional commitment to his success. Since Laura was sensitive to the medical culture of authority, she realised that Dr B. would find it difficult, even risky, to trust her design expertise and accept advice that contradicted his professional enculturation into a moral and intellectual hierarchy with the physician at the head. Laura's design approach involved offering problem based alternatives to the instructor centred, text based presentation of evidence of the medical seminar, talking through the likely outcomes of his instructional ideas and implementing, with empathy, decisions that she knew would not result in successful learning experiences. Laura relates her practice to her goals of social emancipation rooted in the personal values of the community and felt that Dr B's increasing appreciation for instructional design as a valid process was partly grounded in the high value he placed in medical evidence based practice:
I see ... the same parallel in working on a project in instructional design as doing development work in emerging countries ... this comes from my studies in global and human rights education and critical theory ... this has been fundamental in shaping my own philosophy of design and education. Any time an OECD country went in and said, "This is the way we think you should develop...This is the right way, this is our way'... there has been no success.... Social change requires that people change how they are in the world-their thinking-their feelings-their actions- and this is extremely personal. Dr. B. could have come out of that (project) hating technology... but the major change he experienced ... wasn't really his attitude towards technology, but rather his view towards instructional design-- it was like, 'Wow, instructional design is an area of expertise that is necessary and important!'

She believes that change is realised in webs of personal commitments to others and enacts that through an instructional design practice in which "you say, 'We need to foster that change from within... from the grass roots... and I am here to support that'.... Change is a very emotional thing, and I think that is why in order for the course to be successful... it needs to come from his heart."

By supporting Dr B's growing appreciation of inclusive, constructivist learning environments, Laura undergoes a personal transformation that leads her to the next stage of her moral and political growth. Technology can embody her values -- she has to find out how; she can't work in any other context.

I know that I'm not the person that I was when I started.... I am meant to go and have a life of adventure for a while and build and embody what I want my life to be ... the people who make social change happen are people like 
Dr B. .... He embodies what he preaches.... He is such a good, passionate man. He said to me one time, 'I was working with a patient who was your age.... All I could do was go out in my car and cry', and I thought, 'You are the person that I want beside me when I am dying.' ... Those are the people that make the important differences in the world .... I want to embody what I value....

If she was criticised for working with technology, she responded

Yes, but I am working on a Palliative Care project. There's meaning in this.... I don't think I would have stayed as long as I did ...If I couldn't find meaning in the project ... if I didn't find meaning in the people; if I didn't find meaning in supporting their success.

Growing up in a medical culture Laura was well aware of the claims to intellectual, moral and cultural authority, which she challenges through her own commitment to critical education. The personal values she embodies in her instructional design practice -- framed by a critical ethic of care -- are thus interposed within and shaped by "a broader linguistically and culturally determined weave of relationships, interactions, and possibilities making up an ideology or shared worldview" (Herda, 1999, p. 57). Laura enters into an ethical conversation with Dr B. and engages both his world view as a physician and his "disorienting" experience as a learner.

Through the familiar use of case studies and clinical knowledge Laura acts through her ethical knowledge when she asks Dr B. to confront the cultural myths that "structure(s) the individual's taken for granted views of power, authority, knowledge, and identity" (Britzman, 1991, pp. 6-7). By referencing her personal knowledge of physicians' beliefs and practices, she encourages Dr B.'s transformative thinking about power relationships in the health care teams that shape the learning experience in the course. In Herda's (1999) words, the design conversation is ontological in nature "because the cultural reference points that determine our own identity are reinterpreted in view of our personal expectations and singular circumstances" (p. 57). For Laura, this means working with Dr B. and his colleagues in the facilitators' group to explicitly value the knowledge of the "lower status" members of the learning teams, and to insist that the team members value each other.

...remember in the design when (the nurses) came back and said, 'Well, you know, the doctors have said it all already. What is the point in (participating in the collaborative case study and offering our input) ... when the doctors have all the authority?' This was a form of invalidation. As developers and designers, we then went back and said, 'Ok, how can these learners feel valued? What can they bring to the learning that they feel is of value and how as a designer do you build on that?' 
This significant challenge to the learners' personal and social investment in the cultural myth of Medical Authority led to a critical decision: at one point midway through the course the physicians resisted working in collaborative teams in which the voices of nurses and other non-physicians were accepted as equally valid, and demanded to be able to form their own closed team. In intense conversations with Laura in which he struggled with his discipline's expectations of higher status Dr B. (courageously) refused to privilege physician knowing by reorganising the learning teams into separate and unequal disciplines.

Laura characterises this transformative act as reflecting the mutuality of relational design practice. By standing by a learning design decision for social equity and inclusion, she risks her credibility with Dr B. to protect his credibility as a member of an academic and professional community. Dr B. acknowledges Laura's moral agency to affect social change in medical education, by placing his trust in her ethical design knowledge and rejecting certain long held cultural values of medical moral authority.

Ethical knowledge and morally coherent design practice requires an inner ear, tuned to the stories not told and the fears not expressed. A less mature instructional designer might not be aware of her ethical boundaries and where they interact with those of her client, where her zone of influence intrudes in harmful ways on other cultures and discourses, and where there is space for challenge and change. Laura's agentic zone is ultimately bounded and informed by her profound personal relationships, within the framework of her identity as a critical educator.

\section{David and the grand politics of design}

As does Laura, David embodies his values in his design practice, values that derive from his early exposure to labour politics. While Laura acts in individual relationship and emotional connection, David's agency plays out in a broader institutional discourse.

David's career path, like many of the designers in this study, evolved through seemingly serendipitous events that have moral coherence when viewed retrospectively (Schwier, Campbell \& Kenny, 2004). In mid-career he joined a public educational organisation that developed and delivered learning services to adults unable to attend a post-secondary institution. The "social mission" of the agency, related to access to education, appealed to him and, although he enjoyed teaching as an English professor he felt that there were "other people who also enjoy teaching the elite, which is who we were teaching." He describes his "epiphany" as a decision emerging from his personal politics, in that "increasing opportunities for the underprivileged in society has always been an interest and I've always 
felt, obviously, education is an important aspect of improving people's lives."

David's father was a radical labour leader who, in the mid 1930s, organised a pacifist "sit down" involving 1500 unemployed workers, for which he was subsequently jailed. David's family fled to a remote part of the province where he grew up with a "working class, union based, multicultural mix of connections."

One of the interesting things about (that) industry is that there are all sorts of races and interesting people that show up in those (camps) ... so the people we knew were the fellow workers, and they were Chinese, East Indian.... A fair number of First Nations people and so the children of these workers were my playmates and friends as I grew up.

Attracted by the politics of Canadian literature David attended a university well known for its left leaning politics in the 1970s, where he became involved in student government. The opportunity to join the learning organisation also reconnected him with marginalised communities such as the First Nations group who was one of the "forward looking nations and individual bands within that were looking to taking over or getting more control over their own education." David explicitly supports this project of appropriation as a cultural and moral issue by subverting the administrative practices of his organisation: he assumes the authority to facilitate partnerships that are defined by the community stakeholders rather than the bureaucracy, and directly approaches policy makers at the highest levels of the provincial education ministry.

(I) set up a number of sort of partnerships, collaborations, with the First Nations schools (who) were doing Adult Ed and college level programming and university transfer level programming.... Not all of them were remote ... but what they were short of was curriculum and accreditation and so with that kind of partnership then allowed them to have our accreditation. They would use our courses but they would use them most often in the face to face situation, delivered by the teachers in the First Nations college or school. So they were sort of transforming distance education materials and methodology to the local sites. It's been sort of a practice that gets me in hot water now and then, but everybody needs hot water now and then...once the idea sort of struck, I started contacting other groups and they networked fairly well themselves, so other people would contact me as well saying, 'Hey, this is interesting. We would like to get onboard too.' I'd say, 'Fine! Let's do it.' There were about 23 different First Nations groups.

Like Laura, David reflects moral coherence, or "thoughtful agency" (London Feminist Salon Collective, 2004) in that he is conscious of and acts out of a consistent ideology in the organisations and institutions in which he works; while Laura's practice seems grounded in the gentle reciprocity 
of personal relationships, David's language reflects his political enculturation in disruption of the dominant discourse. He sees the potential of instructional design in "subverting the traditional system" depending on the context of which the designer is part. Although he acknowledges that an "instructional designer in a very highly regarded research university might do very good work in helping transform teaching in better ways for the elite" and is "valuable," he prefers to spend his agentic capital on "quality education that's equal to what the elite are offered." He is critical of the "second class" status of distance education, knowing that "there's all sorts of reasons why people don't get on that sort of traditional high class, upper class route" and that excluded communities of learners, such as First Nations and women, continue to be marginalised by the irony of technologies that simultaneously increase and limit access while maintaining the lower status of its users. Although an apparent contradiction, his move from an organisation that was responding directly to these issues to a large, research university reflects a moral coherence because "it was intriguing to think, 'Well, how can we make it better for students at (this traditional university) and possibly even open things up a bit (here)?' because the lifelong learning aspect has always been really important to me.". Proud of the organisation's learner demographics -- 60$70 \%$ women with an average age of 35 to 46 -- he thought,

This could be interesting with the university's (cultural) mix and also with (a colleague's) international work, because one of the advantages, if you can get out into the rest of the world and influence that, then you can bring that back to your own institution and kind of leverage that to make some changes there.

David raises issues of knowledge representation in dominant forms that are "institutionally controlled" but represented as neutral: Britzman's (1991) monological knowledge.

That was one of the issues I had with broadcast ... 75\% of the people had VCRs and we should be designing our media pieces for the VCR.... I tried to explain that broadcast is institutionally controlled and VCR can be learner controlled.... Because what was always an issue for me with broadcast was that as a student you're certainly going to learn something but you just don't have any sort of control over what's gone zinging by and how are you going to apply it and what sort of deeper learning activities opportunities do you have.

And he underlines his ethical knowledge in action by relating an example of his practice for which he typically addresses a larger social issue, that is, animal research. One of his instructional design projects involved the development of a curriculum based on the Canada Council ethical guidelines for animal care. His moral entree was that "researchers aren't doing more harm than they need to do to animals." But he found it difficult 
to reconcile his personal value for animal life with "a kind of animal slavery and... the larger philosophical issues of what are beings." In the end, David saw an opportunity to subvert the discourse through design activism: he engaged the subject matter expert throughout the project in a critical conversation about the morality of research that privileges human needs over the "right of every living thing... to be untouched and left alone."

Whereas Laura's focus is on personal transformation of self and faculty with whom she works, David's goal is the "development of the social citizen" by confronting the "corporatisation" of universities that "have very little to do with education any more" and that feed students' expectations that if they study hard they will "learn what they need to be successful at the job and get up the corporate ladder." David's commitment, to increasing access to curriculum associated with cultural power through distance delivery, is a political ideological choice that he anticipates will address inherent "inequities and substandard" access for both undergraduate and alternate learning communities.

\section{Conclusion: Implications of agency for instructional design practice and education}

Although the field is evolving, the dominant discourse of instructional design -- that it is a set of scientific principles embedded in a rational, technical process operating outside of, or in spite of, social, political, cultural, and personal contexts -- deskills the instructional designer in higher education institutions in fundamental human ways. We maintain that instructional design is a moral practice that embodies the "relationship between self concept and cultural norms, between what we value and what others value, between how we are told to act and how we feel about ourselves when we do or do not do act that way" (Anderson \& Jack, 1991, p. 18). Instructional design involves the ethical knowledge of the designer acting in moral relationship with others in a dialogue among curriculum, the sources and forms of knowledge and power, and the social world. As ethical actors in that world we use the language of design in collaborative conversation with our colleagues, our clients, and our institutions to create an alternate social world of access, equity, inclusion, personal agency and critical action. Herda (1999) captures this notion of transformative social change when she credits language with a "generative role in enabling us to create and acknowledge meaning as we engage in discourse and fulfill social obligations...(that) are characterised as moral activities" (p. 24).

Agency refers to doing and implies power (Hartman, 1991). Designer agency develops into a positive social force when designers have the moral 
space and authority for the reflexive practice that makes available critical relationships to knowledge (Britzman, 1991).

Referring to the coupling of knowledge and power, James Donald (1979) argues that agency can only be understood and become a directed source of personal and political power if "it is conceived not just as a source of social change, but above all, as an effect of particular social and institutional practices" (in Britzman, 1991, p. 37). What then are the implications for instructional design practice that is transformational; that contributes in significant ways to the public good?

We believe that designers are not technicians who simply implement techniques and principles, although when challenged they can certainly use that language to describe what they do, but are principled actors whose practices embody core values, and are represented by moral language and political acts. What could we achieve if we were thoughtful, deliberate, and unapologetic in aligning design projects with the ethical knowledge of designers? If we developed a community in which the moral dimensions of practice were explicitly developed through reflexive dialogue? If we publicly explored the "conscious and unconscious influences on (our) practice and personal resistances to change" (Kugelmass, 2000, p. 179) by asking ourselves: Who am I, why am I practising this way, and what effect does this have on others?

Goodson and Cole (1994) described the developmental circle of novice teachers as they participated in a reflexive project of sustained, critical conversation with their peers. Over time the teachers talked less about the technical aspects of their practice, and more about effecting substantive change in their schools and communities: "Broadly stated, the teachers expanded their conceptions of teaching and themselves as teachers from an early image of teacher as classroom technician to one of teacher as agent of change" (p. 96). We need to articulate our experiences, make connections with ourselves, challenge theory and theorise our practice before we can influence institutional change. We must move beyond lamenting the failure of designers to faithfully implement the theoretical models of design at a micro-level, and inquire into "the epistemology of practice" that is complex, ill-structured, situational, and value laden.

How might we redefine the curriculum in graduate programs of instructional design? Several possibilities exist within the framework of critical, moral practice. For example, engaging pre-service designers early in identity work through approaches such as autobiographical writing, providing more situated experiences that are then deconstructed in group conversations, working with cases based on ethical dilemmas, developing international links and project teams that challenge cultural assumptions 
about learning, internships - these are a few of the activities embodied in the change management process. Further, the focus in many course on the mastery of tools should be re-examined.

In the meantime, since most graduate programs of professional preparation in educational technology are silent on these issues, narrative communities seem the best sites for this inquiry as designers rehabilitate their identities and "emplot" new narratives that effect structural changes in their institutions (Hartman, 1991). We are listening closely to the stories of the designers for hints for harnessing the transformational power of community.

\section{Acknowledgment}

This research was supported by a grant from the Social Sciences and Humanities Council of Canada.

\section{References}

Anderson, K. \& Jack, D.C. (1991). Learning to listen: Interview techniques and analyses. In S.B. Gluck \& D. Patai (Eds), Women's words: The feminist practice of oral history (pp11-26). NY: Routledge.

Andrews, D.H. \& Goodson, L.A. (1991). A Comparative Analysis of Models of Instructional Design. In G. J. Anglin (Ed.), Instructional Technology, Past, Present, and Future (pp. 133-155). Eaglewood, CO: Libraries Unlimited. (Reprinted from Journal of Instructional Development, 3(4), 2-16).

Bolman, L.G. \& Deal, T.E. (1997). Reframing organisations. Artistry, choice and leadership. San Francisco: Jossey-Bass.

Braden, R.A. (1996). The case for linear instructional design and development: A commentary on models, challenges and myths. Educational Technology, 36(2), 5-23.

Britzman, D.P. (1991). Practice makes practice: A critical study of learning to teach. Albany, NY: SUNY Press.

Carter, V.K. (2000). Virtual shades of pale: Educational technologies and the electronic "other". In N.M. Rodriguez and L.E. Villaverde (Eds.), Dismantling white privilege: Pedagogy, politics and whiteness (Counterpoints, Vol. 73) (pp. 25-40). New York: Peter Lang.

Cennamo, K., Abell, S. \& Chung, M. (1996). A “layers of negotiation" model for designing constructivist learning materials. Educational Technology, 36(4), 39-48.

Christians, C.G. (2000). Ethics and politics in qualitative research. In N.K. Denzin \& Y.S. Lincoln (Eds), Handbook of qualitative research (2nd edition) (pp 133-155). London: Sage Publications, Inc.

Cobb, P. (1996). Where is the mind? A coordination of sociocultural and cognitive constructivist perspectives. In C.W. Fosnot (Ed), Constructivism: Theory, perspectives and practice. New York: Teachers College Press. 
Conle, C. (2000). Narrative inquiry: Research tool and medium for professional development. European Journal of Teacher Education, 23(1), 49-63.

Dick, W. (1996). The Dick and Carey Model: Will it survive the decade? Educational Technology Research and Development, 44(3), 55-63.

Dick, W. \& Carey, L. (1996). The systematic design of instruction (4th ed.). Glenview, IL: Scott, Foresman.

Donald, J. (1979). Green paper: Noise of crises. Screen Education, 30, 13-49.

Ewing, J.M., Dowling, J.D. \& Coutts, N. (1998). Learning using the World Wide Web: A collaborative learning event. Journal of Educational Multimedia and Hypermedia, 8(1), 3-22.

Francis, B. (1999). Modernist reductionism or post-structuralist relativism: Can we move on? An evaluation of the arguments in relation to feminist educational research. Gender and Education, 11(4), 381-393.

Fullan, M. (2001). Leading in a culture of change. San Francisco: Jossey-Bass.

Fullan, M. (2004). Leadership and sustainability: System thinkers in action. Thousand Oaks, CA: Corwin Press.

Garrison, D.R. (1993). A cognitivist constructivist view of distance education: An analysis of teaching-learning assumptions. Distance Education, 14(2), 199-211.

Glaser, R. (1991). The maturing of the relationship between the science of learning and cognition and educational practice. Learning and Instruction, 1(2), 129-144.

Goodson, I. (1994). Studying the teacher's life and work. Teaching and Teacher Education, 10(1), 29-37.

Goodson, I. (1995). Storying the self: Life politics and the study of the teacher's life and work. Paper presented at the annual meeting of the American Educational Research Association, San Francisco, CA.

Goodson, I.K. \& Cole, A.L. (1994). Exploring the teacher's professional knowledge: Constructing identity and community. Teacher Education Quarterly, 21(1), 85-105.

Gustafson, K.L. \& Branch, R.M. (1997). Survey of instructional development models (3rd ed). Syracuse, NY: ERIC Clearinghouse on Information and Technology.

Hannafin, M., Land, S. \& Oliver, K. (1999). Open learning environments: Foundations, methods and models. In C.M. Reigeluth (Ed.). Instructional-design theories and models, Volume II: A new paradigm of instructional theory. Mahwah, NJ: Lawrence Erlbaum Associates.

Hartman, J.E. (1991). Telling stories: The construction of women's agency. In Joan Hartman \& Ellen Messer-Davidow (Eds), (En)gendering knowledge: Feminists in academe (pp 11-31). Knoxville: University of Tennessee Press.

Herda, E.A. (1999). Research conversations and narrative: A critical hermeneutic orientation in participatory inquiry. London: Praeger.

Heilbrun, C. (1988). Writing a woman's life. New York: Ballantine Books. 
Hill, J.R., Bichelmeyer, B.A., Boling, E., Gibbons, A.S., Grabowski, B.L., Osguthorpe, R.T., Schwier, R.A. \& Wager, W. (2004). Perspectives on significant issues facing instructional design and technology. In M. Orey (Ed), Educational media and technology yearbook, 29, 23-43.

Jonassen, D.H. (1999). Designing constructivist learning environments. In C.M. Reigeluth (Ed), Instructional design theories and models, Volume II: A new paradigm of instructional theory (pp. 215-239). Mahwah, NJ: Lawrence Erlbaum Associates.

Jonassen, D., Dyer, D., Peters, K., Robinson, T., Harvey, D., King, M. \& Loughner, P. (1997). Cognitive flexibility hypertexts on the Web: Engaging learners in making meaning. In B.H. Khan (Ed), Web-based instruction (pp. 119-133). Englewood Cliffs, NJ: Educational Technology Publications.

Kenny, R.F., Zhang, Z., Schwier, R.A. \& Campbell, K. (2005). A review of what instructional designers do: Questions answered and questions not asked. Canadian Journal of Learning and Technology, 31(1), 9-16.

Koper, R. (2000). From change to renewal: Educational technology foundations to electronic learning environments. Inaugural address of the Educational Technology Expertise Center, Open University of the Netherlands.

Kugelmass, J.W. (2000). Subjective experience and the preparation of activist teachers: Confronting the mean old snapping turtle and the great big bear. Teaching and Teacher Education, 16, 179-194.

London Feminist Salon Collective (2004). The problematization of agency in postmodern theory: As feminist educational researchers, where do we go from here? Gender and Education, 16(1), 25-33.

Mayer, R.H. (1999). Designing instruction for constructivist learning. In C. M. Reigeluth (Ed), Instructional design theories and models, Volume II: A new paradigm of instructional theory (pp. 141-159). Mahwah, NJ: Lawrence Erlbaum Associates.

Merrill, M.D. (2002). First principles of instruction. Educational Technology, Research and Development, 50(3), 43-60.

Merrill, M.D., Drake, L., Lacy, M.J., Pratt, J. \& the ID2 Research Group (1996). Reclaiming instructional design. Educational Technology, Sept/Oct, 5-7.

Morrison, G.R., Ross, S.M. \& Kemp, J.E. (2004). Designing effective instruction. Hoboken, NJ: John Wiley \& Sons.

Reigeluth, C.M. (1996). A new paradigm of ISD? Educational Technology, 36(3), 13-20.

Reigeluth, C.M. (1999). What is instructional-design theory and how is it changing? In C. M. Reigeluth (Ed), Instructional design theories and models, Volume II: A new paradigm of instructional theory (5-29). Mahwah, NJ: Lawrence Erlbaum.

Saettler, P. (1992). A history of instructional technology. New York: McGraw-Hill.

Shambaugh, R.N. \& Magliaro, S.G. (2001). A reflexive model for teaching instructional design. Educational Technology Research and Development, 49(2), 69-91.

Schwier, R.A., Campbell, K. \& Kenny, R. (2003). Instructional designers' interpretations of their communities of practice. In M. Simonson (E.), Proceedings of Selected Research and Development Paper Presentations, Association for Educational Communications and Technology (AECT), Anaheim, California. 
Schwier, R.A., Campbell, K. \& Kenny, R.F. (2004). Instructional designers' observations about identity, communities of practice and change agency. Australasian Journal of Educational Technology, 20(1), 69-100. http://www.ascilite.org.au/ajet/ajet20/schwier.html

Seels, B. \& Glasgow, Z. (1998). Making instructional design decisions (2nd ed.). Upper Saddle River, NJ: Merrill Prentice Hall.

Smith, P.L. \& Ragan, T.J. (2005). Instructional design (3rd ed.). Hoboken, NJ: John Wiley \& Sons.

Tergan, S.O. (1997). Misleading theoretical assumptions in hypertext/hypermedia research. Journal of Educational Multimedia and Hypermedia, 6(3/4), 257-283.

Vrasidas, C. (2001). Constructivism versus objectivism: Implications for interaction, course design, and evaluation in distance education. International Journal of Educational Telecommunications, 6(4), 339-362.

Weick, K.E. \& Quinn, R.E. (1999). Organizational change and development. Annual Review of Psychology, 50, 361-86

Willis, J. (1998). Alternative instructional design paradigms: What's worth discussing and what isn't? Educational Technology, 38(3), 5-16.

Willis, J. (2000). The maturing of constructivist instructional design: Some basic principles that can guide practice. Educational Technology, 40(1), 5-16.

Wood, D.R. (1992). Teaching narratives: A source for faculty development and evaluation. Harvard Educational Review, 62(4), 535-550.

Katy Campbell PhD, Associate Dean, Faculty of Extension 2-02 University Extension Centre

University of Alberta, Edmonton, AB, Canada T6G 2T4

Phone: (780) 4921858 Email: katy.campbell@ualberta.ca

Richard A. Schwier EdD, Professor, Educational Communications and Technology, College of Education, 28 Campus Drive

University of Saskatchewan, Saskatoon, SK, Canada S7N 0X1

Phone: (306) 9667641 Email: richard.schwier@usask.ca

Richard F. Kenny $P h D$, Associate Professor

Centre for Distance Education, Athabasca University,

1 University Drive, Athabasca, AB, Canada T9S 3A3.

Phone: (250) 7032040 Email: rickk@athabascau.ca 